\title{
HEARING LOSS, ITS IMPLICATIONS AND PUBLIC HEALTH INTERVENTIONS
}

\author{
Suneela Garg1, Kalika Gupta ${ }^{2}$
}

1 Director Professor, Department of Community Medicine, Maulana Azad Medical College, New Delhi.

2Post Graduate Resident, Department of Community Medicine, Maulana Azad Medical College, New Delhi.

\begin{abstract}
Globally, over 5\% of world's population (More than 360 million population), have disabling hearing loss according to new global estimates on prevalence; $91 \%$ of these are adults and $9 \%$ of these are children. Overall, prevalence of disabling hearing loss in children all over the world is $1.7 \% .^{1}$ Prevalence of hearing loss in South Asia in pediatric age group is $2.4 \%$. Consequences of hearing impairment include inability to interpret speech sounds, often producing a reduced ability to communicate, delay in language acquisition, economic and educational disadvantage, social isolation and stigmatization. Fifty percent of hearing loss is preventable through public health actions. ${ }^{1}$ From time to time, public and private sector enterprises plan at both, small and large scale to help people with hearing impairment. But still the services available and implementation status of actions to combat ear disorders is in naïve stage. The earlier the parent/family accept the fact of impairment and follow a well-planned rehabilitation program under professional supervision, the better are the chances for the child and the family to lead a more normal life.
\end{abstract}

\section{KEYWORDS}

Hearing Loss, Implications, Public Health Interventions.

HOW TO CITE THIS ARTICLE: Suneela Garg, Kalika Gupta. "Hearing Loss, its Implications and Public Health Interventions." Journal of Evolution of Medical and Dental Sciences 2015; Vol. 4, Issue 98, December 07; Page: 16385-16386,

DOI: $10.14260 /$ jemds/2015/2423

\section{INTRODUCTION}

Globally, over $5 \%$ of world's population (More than 360 million population), have disabling hearing loss, according to new global estimates on prevalence released by the WHO for International Ear Care Day (3 March, 2013). Of the total, 91\% of these are adults and $9 \%$ of these are children. Disabling hearing loss refers to hearing loss greater than 40 decibels $(\mathrm{dB})$ in the better hearing ear in adults and a hearing loss greater than $30 \mathrm{~dB}$ in the better hearing ear in children. The majority of people with disabling hearing loss live in low- and middle-income countries. The prevalence of disabling hearing loss in children is greatest in South Asia, Asia Pacific and SubSaharan Africa. Overall, prevalence of disabling hearing loss in children all over the world is $1.7 \% .{ }^{1} \mathrm{~A}$ person who is not able to hear as well as someone with normal hearing hearing thresholds of $25 \mathrm{~dB}$ or better in both ears - is said to have hearing loss. Prevalence of hearing loss in South Asia in pediatric age group is $2.4 \% .^{1}$

Prevalence of Disabling Hearing Loss among men and women in South Asia are $9.5 \%$ and $7 \%$, prevalence in South Asian children is 2.4\%. Approx. 0.5-5 of every 1000 infants are born with or develop in early childhood disabling hearing loss. ${ }^{1}$ The prevalence of disabling hearing loss increases with age, i.e. prevalence in children is $1.7 \%$, in adults aged 15 years or more it is around $7 \%$, rapidly increasing to almost one in three in adults older than 65 years. In most regions, prevalence in children decreases linearly as parent's literacy rate increases. In adults 65 years and older, prevalence decreases exponentially as income increases. ${ }^{2}$

\section{CONSEQUENCES OF HEARING IMPAIRMENT}

Consequences of hearing impairment will depend on the ear/s involved, the degree and the type of hearing loss and

Financial or Other, Competing Interest: None.

Submission 10-11-2015, Peer Review 11-11-2015,

Acceptance 27-11-2015, Published 07-12-2015.

Corresponding Author:

Dr. Kalika Gupta,

E! /231, Sector-11,

Rohini, Delhi.

E-mail: kalikagupta007@gmail.com

DOI: $10.14260 /$ jemds $/ 2015 / 2423$ the age of onset. Due to distortion of sounds, differentiation of environmental sounds including speech is difficult; making sounds louder does not improve the clarity or quality of sound. Similarly, recruitment which is an abnormal growth in loudness, a characteristic of damage to the inner ear makes it difficult to tolerate loud sounds. For children with hearing impairment, congenital or acquired before development of speech and language, normal speech development is interfered with. With unilateral hearing impairment also there is difficulty in localizing sound, reduced speech discrimination. ${ }^{3}$

Consequences include inability to interpret speech sounds, often producing a reduced ability to communicate, delay in language acquisition, economic and educational disadvantage, social isolation and stigmatization. Communication and behavioral skills are influenced by a child's ability to hear. Hearing loss affects a child's social interaction, memory, comprehension and vocabulary development, emotional development, academic performance, speech perception and production.

Children suffer from self-described feelings of isolation, exclusion, embarrassment, annoyance, confusion and helplessness. Barriers for seeking ear care services like social stigma related to diseases, lack of awareness, shortage of human resources, quacks treating wrongly, late identification of the problems, etc. need to be managed effectively. Hence, it is pertinent to review the current scenario of otological morbidities in Indian children and suggest possible interventions to fight against all odds.

Fifty percent of hearing loss is preventable through public health actions. ${ }^{1}$ Therefore, through appropriate public health measures, current burden of ear morbidities can be halved. Therefore for this, we need to know the strengths and weaknesses of our Health Care System.

\section{PUBLIC HEALTH MEASURES ${ }^{3}$}

From time to time, public and private sector enterprises plan at both small and large scale to help people with hearing impairment. But still the services available and implementation status of actions to combat ear disorders is in naïve stage. 
In 2006, World Health Organization (WHO) released a new set of training manuals aimed at equipping health care workers in developing countries with simple and costeffective methods to reduce deafness and hearing problems through actions at the primary level of health care. The Primary Ear and Hearing Care Training Resource addresses the urgent need for action to prevent and manage ear diseases and hearing impairment. They are designed to be useful to a wide range of people from village health workers to more experienced health care personnel.

The manuals can also be used to help communities understand common causes of deafness and hearing impairment and ways to prevent and/or treat the conditions. Vaccination against childhood diseases that can cause hearing impairment, good ear hygiene, appropriate use of medication, and avoidance of excessive noise are examples of simple ways of preventing deafness and hearing impairment. ${ }^{4}$

Education of children with hearing impairment in India is just a little over a hundred years old. After Independence, improvements were seen with the establishment of many new schools in the 1950s and many programs based on the new technology came up in the 1960s. The sixties saw the establishment of the All India Institute of Speech and Hearing in Mysore, where facilities for diagnosis of hearing impairment in infants and young children were available. At present, over 500 schools for the hearing impaired children are available in the country. The Government established and administers some schools, whereas the NGOs run many others.

Most of the schools, still residential, admit children aged 5 years and above who spend the entire school year in the hostels; they go home only during summer vacation. Provision of vocational courses and sheltered workshops facilitates spending almost the entire lifetime of some students in these schools. Two colleges for the Deaf, one in Chennai, Tamil Nadu affiliated to the University of Madras and another in Valakom, Kerala, conduct degree courses in Commerce and Art subjects; a third program is under the Indira Gandhi National Open University, New Delhi. Educating children with multiple disabilities is a difficult task. In India training programs to train teachers to help children who are 'deaf-blind' has only recently begun. ${ }^{3}$

We need to make constructive efforts towards early diagnosis and treatment of hearing disorders. The issues in early identification to be addressed are (i) Population/location of screening, (ii) Technique/tools for screening, (iii) Human resources for screening, (iv) Cost, (v) Challenges in screening, and (vi) Intervention for the identified.

Few projects have been started with the aim of early diagnosis and treatment of hearing disorders. Under the Project of Prevention of Deafness undertaken at All India Institute of Speech and Hearing, Mysore, funded by the Ministry of Health and Family Welfare, Government of India, Yathiraj et al. (2002) reported screening of 28,750 infants over a period of five years.

The Ministry of Health and Family Welfare, Government of India in 2006, launched the pilot phase of the National Programme in Prevention and Control of Deafness.
One of the objectives is early identification, diagnosis and treatment of hearing loss. The services/facilities available for early intervention in the country are covered under the following: (i) Medical intervention, (ii) Aids, appliances and cochlear implant, and (iii) Auditory and speech-language training. ${ }^{3}$

Educating children with multiple disabilities is a difficult task. In India training programs to train teachers to help children who are 'deaf-blind' has only recently begun.

\section{REHABILITATION}

The earlier the parent/family accept the fact of impairment and follow a well-planned rehabilitation program under professional supervision, the better are the chances for the child and the family to lead a more normal life. Parental attitudes towards disability include inter alia acceptance, rejection, indifference and overprotection. Some parents work towards the development of the child, but feel the need to shelter and protect because of the disability. Overprotection denies the child the opportunity to achieve his potential in various areas of development. ${ }^{3}$

Rehabilitation of persons with disabilities has gained momentum in India during the last decade with several states as well as the Union Government launching programs for their benefit. Community Based Rehabilitation and Integrated Child Development schemes are two major thrust areas in this endeavor.

On account of the multidimensional facets of hearing impairment, $\mathrm{R}$ and $\mathrm{D}$ activities call for in depth studies, both inter and multi-disciplinary. This calls for synchronized development in the core discipline as well as in allied disciplines. Achievements in technology, bio-technology, information technology, and digital technology have ushered in developments in accessibility to digital programmable hearing aids, cochlear implant surgery, related rehabilitation technology and auditory genetic diagnosis.

Exploration of indigenous technology and techniques is crucial to bring benefits of technological advances within the reach of the economically weakest among the disabled to meet their needs, whether for identification/diagnosis or habilitation/rehabilitation. ${ }^{3}$

\section{REFERENCES}

1. Prevention of blindness and deafness [Internet]. World Health Organization. (Cited 2012, Accessed 2015 Aug 10). Available from: http://www.who.int/pbd/deafness/estimates/en/.

2. Global estimates on prevalence of hearing loss [Internet]. WHO. (Cited 2012, Accessed 2015 Aug 13).

3. Hearing impairment [Internet]. World Health Organization. (Accessed 2015 Aug 10). Available from: http://www.rehabcouncil.nic.in/writereaddata/hi.pdf.

4. World health organization. New WHO training manuals aim to improve hearing care in developing countries [Internet]. Geneva: WHO; 7/3/2006.

(Accessed 2015 Aug 14). Available from: http://www.who.int/mediacentre/news/new/2006/n w01/en/. 